\title{
Micropropagation and Composition of Essentials Oils in Garden Thyme (Thymus vulgaris L.)
}

\author{
Danuta KULPA ${ }^{1 *}$, Aneta WESOŁOWSKA², Paula JADCZAK ${ }^{1}$ \\ ${ }^{1}$ West Pomeranian University of Technology, Department of Plant Genetics, Breeding and Biotechnology, Slowackiego 17, 71-434, Szczecin, \\ Poland;danuta.kulpa@zut.edu.pl (*correspondingauthor);paula.jadczak@zut.edu.pl \\ ${ }^{2}$ West Pomeranian University of Technology, Department of Organic and Physical Chemistry, Aleja Piastów 42, 71-065 Szczecin, \\ Poland; aneta.wesotowska@zut.edu.pl
}

\begin{abstract}
Thymus vulgaris $\mathrm{L}$. is an important aromatic plant, because of the synthesis and production of its essential oils for the pharmaceutical and cosmetic industries. In this study, we developed a micropropagation protocol for T. vulgaris 'Słoneczko' and evaluated the potential of micropropagated plants for essential oil production with industrial application. The seeds were soaked for $10 \mathrm{~min}$ in $10 \%$ sodium hypochlorite $(\mathrm{NaOCl})$ solution. Then, each seed was put into a $20 \mathrm{ml}$ test tube filled with $5 \mathrm{ml}$ of Murashige and Skoog (MS) medium. Half of the cultures were subjected to light intensity which was maintained at 40 $\mu \mathrm{Em}^{-2} \mathrm{~s}^{-1}$, and the other half was cultured in the dark. Shoot explants were multiplied in vitro using MS medium supplemented with BAP, 2iP or KIN. The results obtained indicate that the cytokinin which had the most positive impact on plant development at the multiplication stage was $5 \mathrm{mg} \mathrm{dm}^{-3} 2$ iP. Single-node fragments of shoots cultured on MS medium without plant growth regulators were transferred to MS medium supplemented with IAA, IBA and NAA at concentrations of 0.2, 0.5, 1 and $2 \mathrm{mgdm}^{-3}$. The best rooting of shoots was obtained on MS medium supplemented with $2 \mathrm{mgdm}^{-3} \mathrm{IBA}$. The essential oils obtained by hydrodistillation in Deryng and Clevenger apparatus from in vitro shoot cultures of $T$. vulgaris L. were analysed using gas chromatography-mass spectrometry (GC-MS). Analysis revealed the presence of 54 components represented mainly by oxygenated monoterpenes (56.81-57.28\%) and monoterpene hydrocarbons (31.90-33.72\%). Among identified constituents, the most abundant were thymol (33.37-34.05\%), $\gamma$-terpinene (11.62-11.91\%), p-cymene (9.81-10.07\%), carvacrol (5.63-5.96\%), carvacrol methyl ether (3.86-3.87\%) and linalool (3.16-3.36\%).
\end{abstract}

Keywords: in vitro; Lamiaceae; volatile oils

\section{Introduction}

Thymus vulgaris $\mathrm{L}$. (garden thyme) from the Lamiaceae family is one of the most widely used aromatic plants. The dried leaves and flowering tops are employed as flavouring agents for food and beverages, and as sources of essential oil for the pharmaceutical and cosmetic industries. Thyme is an important medicinal plant, and essential oils extracted from the plant, commonly known as thyme oils, have a wide range of therapeutic applications and properties including antirheumatic, antiseptic, antibacterial, carminative, diuretic and expectorant (Deans and Ritchie, 1987; Tabak et al., 1996; Cosentino et al., 1999; Grigore et al., 2010; Mirzaei-Aghsaghali et al., 2012; Nikolič et al., 2014). Essential oils stimulate the immune system to fight colds and flu and aid in tackling infectious diseases (Nikolič et al., 2014). Moreover, essential oils are also used in food as well as the textile industry (Hazzit $e$ t al., 2009). The oils are also applied in a wide range of oral hygiene products, and as fragrance components in soaps, cleansers and other toiletries (Leung and Foster, 1996). Thyme essential oil is well recognised for its medicinal properties. The principal constituents of thyme oil are: thymol (20-80\%), p-cymene (9-43\%), limonene (0.2-24\%), $\gamma$-terpinene (0-13\%) and carvacrol (0.5-6\%) (Blum et al., 1997; Lee et al., 2005; Nickavar et al., 2005).

Plant tissue culture, known as micropropagation, offers independence from climatic factors, elimination of geographical and political boundaries, shorter production cycles and novel products not found in nature. In recent years, there have been numerous publications on micropropagation of various species of the thyme genus: $T$. bleicherianus (Nordine and El Meskaoui, 2014), T. caespititius (Mendes et al., 2013), T. daenensis (Bernard et al., 2015; Hassannejad et al., 2012), T. hyemalis (Nordine et 
526

al., 2013a), T. satureioides (Nordine et al., 2013b), T. longicaulis (Ozudogru et al., 2011), T. lotocephalus (Coelho et al., 2012), T. mastichina (Fraternale et al., 2003; Mendes and Romano, 2009), T. membranaceus (Pérez-Tortosa et al., 2012), T. moroderi (Marco-Medina and Casas, 2015), T. persicus (Bakhtiar et al., 2014; Tavan et al., 2015), T. piperella (Saez et al., 1994), T. marschallianus Willd. and $T$. serphyllum (Sargsyan et al., 2011).

Even though $T$. vulgaris is the most common species of this genus and is grown in large areas, scientific literature on the possibilities of propagation of this species in in vitro cultures is not extensive and the results presented therein are often divergent. Research on propagation of in vitro thyme cultures was initiated by Olszowska and Furmanowa (Furmanowa and Olszowska, 1980; Olszowska, 1982; Olszowska and Furmanowa, 1987). The aforementioned authors multiplied the plants on modified NN medium with addition of $10 \mathrm{mgdm}^{-3}$ adenine sulphate (AS) and 0.5 $\mathrm{mg} \cdot \mathrm{dm}^{-3} \mathrm{IBA}$. Their research also allowed for determination of the concentration of essential oils in plant tissues regenerated in in vitro cultures.

Ozudogru et al. (2011) investigated the effect of plant growth regulators on the multiplication of selected thyme species including common thyme ( $T$. vulgaris) in in vitro cultures. The experiments conducted by the researchers allowed for determination of the effect of Murashige and Skoog (MS) medium with cytokinins (BAP, KIN and TDZ), used separately and in combination with auxins and gibberellins, on the development of the plant. In order to optimise the process of shoot proliferation, silver nitrate was added to the culture medium. The highest growth rate was obtained using semi-solid MS medium supplemented with $1 \mathrm{mgdm}^{-3} \mathrm{GA}_{3}$, and MS medium supplemented with 0.05 $\mathrm{mgdm}^{-3} 2,4-\mathrm{D}$ showed greatest efficiency at the rooting stage.

Selection of the appropriate medium is crucial for obtaining desired results in in vitro cultures. Therefore, this study attempts to identify the most efficient method of micropropagation of thyme (T. vulgaris) in in vitro plant cultures. On the other hand, the quantity of essential oil and its composition may be dependent on the regeneration conditions (Andrys et al., 2017; Andrys and Kulpa, 2017). Moreover, biologically active compounds may be accumulated in in vitro cultures athigher concentrations than in intact plants (Gounaris, 2010, Matkowski, 2008).The aim of the conducted study was to determine the method of thyme multiplication in in vitro cultures at the initiation, multiplication and rooting stages, and to determine the chemical composition of essential oils isolated by hydrodistillation in Deryng and Clevenger apparatus from in vitro shoot cultures of Thymus vulgaris L.

\section{Materials and Methods}

\section{Culture initiation}

Seeds of the 'Słoneczko' cultivar of thyme (T. vulgaris) were used to set up the experiment. The seeds were washed for $15 \mathrm{~min}$ under running tap water and soaked for $10 \mathrm{~s}$ in $70 \%$ ethyl alcohol and then for $10 \mathrm{~min}$ in $10 \%$ sodium hypochlorite solution $(\mathrm{NaOCl})$. Decontaminated seeds were rinsed three times with sterile distilled water and blotted dry on sterile absorbent paper, and then each seed was put into a $20 \mathrm{ml}$ test tube filled with $5 \mathrm{ml}$ of MS medium of mineral concentration as specified by Murashige and Skoog (1962). At this stage of the experiment, as well as at subsequent stages, the medium was supplemented with $30 \mathrm{gdm}^{-3}$ sucrose, $100 \mathrm{mgdm}^{-3}$ inositol, and agar at a concentration of $7 \mathrm{gdm}^{-3}$ (Plant Propagation Agar Biocorp); the $\mathrm{pH}$ of the medium was adjusted to 5.7 with $0.1 \mathrm{M} \mathrm{HCl}$ and $\mathrm{NaOH}$ solutions. Depending on the stage of the experiment, the test tubes or jars were autoclaved at a temperature of $121{ }^{\circ} \mathrm{C}$ for $20 \mathrm{~min}$ following the potential addition of plant growth regulators to the medium. The established cultures were transferred to a phytotron in which air humidity was adjusted to $70-80 \%$ and temperature to $24 \pm 1^{\circ} \mathrm{C}$. Lighting time was $16 \mathrm{~h}$ a day, and light intensity was maintained at $40 \mu \mathrm{EM}^{-2} \mathrm{~s}^{-1}$. At the initiation stage, half of the cultures were subjected to the aforementioned conditions, and the other half was cultured in the dark. Each combination comprised 100 seeds. After 4 weeks, the percentage of germinating seeds was determined.

\section{Multiplication stage}

Sterile shoots were initiated to grow, and multiplied twice on a medium of mineral composition as specified by Murashige and Skoog (1962). Single-node shoot fragments of $1-1.5 \mathrm{~cm}$ in length were collected from multiplied plants and cultured on media containing macro- and microelements according to Murashige and Skoog (1962) and supplemented with BAP, $2 \mathrm{iP}$ or KIN at concentrations from 0.5 to $5 \mathrm{mgdm}^{-3}$. For each combination of media, 7 jars were prepared (each jar constituted one replication) and 5 explants were transferred to each medium. The controls were explants cultured on MS medium without growth regulators. After 6 weeks, the following morphological characteristics of the analysed plants were determined: mass, number of shoots and plant height.

\section{Rooting stage}

Single-node fragments of shoots cultured on MS medium without plant growth regulators were transferred to MS medium supplemented with IAA, IBA and NAA at concentrations of $0.2,0.5,1$ and $2 \mathrm{mgdm}^{-3}$. The control was MS medium without plant growth regulators. For each concentration, 7 jars were prepared and 5 thyme explants were placed in each culture vessel. After 4 weeks of culturing, the following features of the analysed plants were determined: mass, height, number of roots and their length.

\section{Isolation of essential oil}

For the isolation of essential oil, the multiplied in vitro shoots were washed of medium and dried at $35^{\circ} \mathrm{C}$ (electric drier). Ten grams of dried plant material (shoot cultures) in a $1000 \mathrm{ml}$ round-bottomed flask along with $400 \mathrm{ml}$ of distilled water was submitted to hydrodistillation for $2 \mathrm{~h}$ using Deryng apparatus recommended by the Polish Pharmacopoeia VI. The hydrodistillation was also performed with the use of Clevenger apparatus for $2 \mathrm{~h}$ in accordance with the recommendations of the European Pharmacopoeia 7.0 (2010). The oil volume was measured directly in the calibrated distillation apparatus tube. Next, after separation from water, the essential oil was dried over 
anhydrous sodium sulphate, filtered and stored in dark sealed vials at $4{ }^{\circ} \mathrm{C}$ until gas chromatography-mass spectrometry (GC-MS) analysis. Two replicates were carried out. Essential oil percentage was calculated based on the dry weight of plant material.

\section{GC-MS analysis of essential oils}

The qualitative GC-MS analysis of the essential oils was carried out using an HP 6890 gas chromatograph equipped with an HP-5MS capillary column $(30 \mathrm{~m} \times 0.25 \mathrm{~mm}$, film thickness $0.25 \mu \mathrm{m}$ ) and directly coupled to an MSD 5973 mass selective detector. Helium $\left(1 \mathrm{mlmin}^{-1}\right)$ was used as a carrier gas. Samples of $2 \mu \mathrm{l}$ ( $40 \mathrm{mg}$ of oil dissolved in $1.5 \mathrm{ml}$ of dichloromethane) were injected in the split mode at a ratio of 5:1. The injector and transfer line were kept at $280^{\circ} \mathrm{C}$. The ion source temperature was $230^{\circ} \mathrm{C}$.

The initial temperature of the column was kept at $40{ }^{\circ} \mathrm{C}$ for $5 \mathrm{~min}$, then increased to $60^{\circ} \mathrm{C}$ at a rate of $30^{\circ} \mathrm{C} \mathrm{min}^{-1}$, next to $230^{\circ} \mathrm{C}$ at a rate of $6^{\circ} \mathrm{C} \min ^{-1}$ (kept constant for 10 $\mathrm{min})$, and then increased to a final temperature of $280^{\circ} \mathrm{C}$ at a rate of $30^{\circ} \mathrm{C} \mathrm{min}^{-1}$. The oven was held at this temperature for $5 \mathrm{~min}$. Mass spectra were taken at $70 \mathrm{eV}$. The mass range was from 40 to $550 \mathrm{~m} / \mathrm{z}$. Solvent delay time was $4 \mathrm{~min}$. The total running time for a sample was about $51 \mathrm{~min}$. The relative percentage of the essential oil constituents was evaluated from the total peak area (TIC) by the apparatus software.

\section{Compound identification}

The components of the isolated essential oils were identified by comparison of their mass spectra with those stored in NIST 2002 and Wiley NBS75K mass spectral libraries and confirmed by comparison of their calculated retention indices (RI) with data available online in the NIST Chemistry WebBook (http://webbook.nist.gov/ chemistry/), the literature (Adams 2007) and our own data for standards ( $\mathrm{p}$-cymene, carvacrol and thymol purchased from Fluka and Sigma-Aldrich).

$\mathrm{RI}$ were calculated for all volatile constituents using a homologous series of $n$-alkanes $\left(\mathrm{C}_{7}-\mathrm{C}_{40}\right)$ under the same chromatographic conditions used for analysis of the essential oils.

\section{Statistical analysis}

The biometric measurement results obtained were developed on the basis of analysis of variance and assessment of the significance of difference at the levels $p=0.05$ and $\mathrm{p}=0.01$. The confidence half-intervals calculated using Tukey's test allowed identification of homogenous groups with significant differences between them. Statistical analysis of the GC-MS analysis (results given in Table 3) was conducted for 20 selected constituents of content greater than $1 \%$ of the essential oil.

\section{Results and Discussion}

\section{Culture initiation}

The culture initiation stage usually requires the primary explants, in this case seeds, to be decontaminated. The decontamination method applied in this experiment (soaking in $70 \%$ ethanol solution, then for $10 \mathrm{~min}$ in $10 \%$ $\mathrm{NaOCl}$ ) proved to be efficient (Fig. 1a, Fig. 2). The seeds started to germinate as soon as 3 days after transferring onto a medium, and after the first week of the experiment, the percentage of germinated seeds cultured in the $16 \mathrm{~h}$ photoperiod was $60 \%$ against $45 \%$ for seeds cultured in the dark. After 4 weeks, in the lighted culture the percentage of seeds which germinated was $80 \%$ in comparison to $50 \%$ in the dark-grown cultures. For most species of the Thymus genus, decontamination of seeds is carried out by soaking in $\mathrm{NaOCl}$ solution ata concentration of $1 \%$ as for T. byemalis (Nordine et al., 2013a) to $5 \%$ as for T. persicus (Bakhtiar et al., 2014) and $T$. lotocephalus (Coelho et al., 2012), or in $0.1 \% \mathrm{HgCl}_{2}$ solution as for T. mastichina (Fraternale et al. 2003). Other agents used for decontamination of $T$. vulgaris seeds were 5\% calcium hypochlorite (Furmanowa and Olszowska, 2009), 20\% NaOCl solution (Karalija and Parić, 2011), or 10\% $\mathrm{H}_{2} \mathrm{O}_{2}$ solution (Ozudogru et al., 2011).

\section{Effect of cytokinins on multiplication of thyme in in vitro cultures}

Our studies show that all applied concentrations of cytokinins had a significant effect on growth reduction. The use of control medium without growth regulators resulted in development of the tallest plants. The shortest plants were cultured on media supplemented with BAP, and the
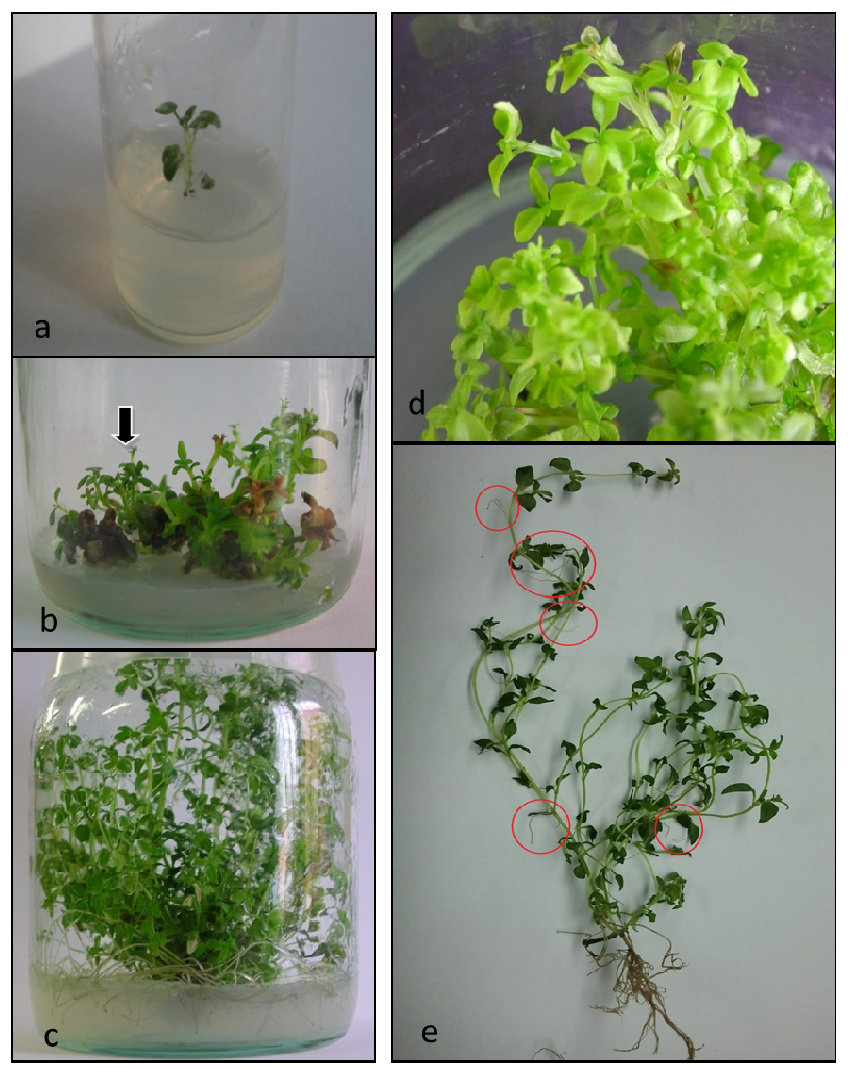

Fig. 1. Micropropagation and callus culture initiation of thyme: a). Germination of seeds on MS medium in cultures lighted with the intensity of $40 \mu \mathrm{Em}^{-2} \mathrm{~s}^{-1}$; b). Hyperhydric shoots (arrow) forming on node explant on MS medium with $1 \mathrm{mg} \cdot \mathrm{dm}^{-1} \mathrm{TDZ}$; c) Thyme shoots rooted on MS

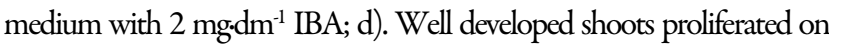

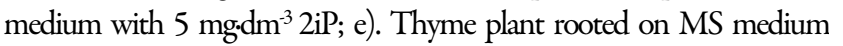
supplemented with $1 \mathrm{mg} \cdot \mathrm{dm}^{-1} \mathrm{IAA}$ with visible roots developed on shoots 


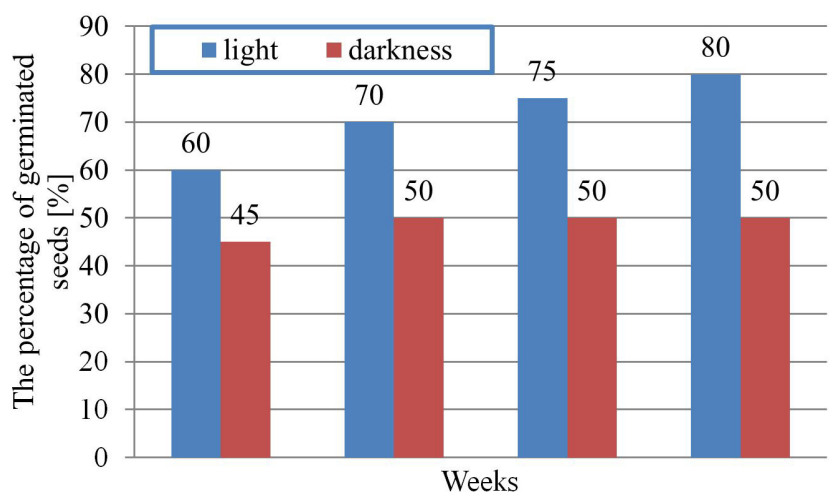

Fig. 2. The percentage of seeds germinated in vitro in the dark and illuminated with light of intensity $40 \mu \mathrm{M} \cdot \mathrm{m}^{2} \cdot \mathrm{s}^{-1}$

height of the plant decreased with the increase in BAP concentration in the medium $(2.6 \mathrm{~cm}$ for the plants on medium with $5 \mathrm{mgdm}^{-3}$ ). According to many authors, multiplication of thyme on media supplemented with cytokinins results in a decrease in shoot height (Nordine and El Meskaoui, 2014). However, the use of this medium also resulted in the development of shoots showing symptoms of hyperhydricity (Table 1, Fig. 1b).

Growth regulators added to media at the multiplication stage are mostly cytokinins added separately or, for the purpose of shoot elongation, in combination with $\mathrm{GA}_{3}$ or auxins. In their extensive research on the effect of cytokinins (6-benzyladenine, kinetin, and thidiazuron) on the multiplication of T. vulgaris and T. longicaulis, Ozudogru et al. (2011, 2012) found semi-solid MS medium supplemented with $1 \mathrm{mgdm}^{-3}$ kinetin and $0.3 \mathrm{mgdm}^{-3} \mathrm{GA}_{3}$ to be the most efficient medium at the multiplication stage. Also, Nordine et al. (2013a) claimed that the best medium to be used at this stage of the experiment was the medium supplemented with $0.5 \mathrm{mgdm}^{-3} \mathrm{KIN}$. The results of our own research show that KIN at a concentration of 0.5 $\mathrm{mgdm}^{-3}$ resulted in development of plants of the lowest mass and smallest number of side shoots. The results obtained indicate that the cytokinin which had the most positive impact on plant development at the multiplication stage was $2 \mathrm{iP}$ (medium supplemented with $5 \mathrm{mgdm}^{-3}$, Fig. 1d). The plants cultured on medium supplemented with this growth regulator at the aforementioned concentration were marked by the greatest mass and number of shoots, which allowed for excision of a higher number of explants at the subsequent stage of the experiment.

\section{Effect of auxins on rooting of thyme in in vitro cultures}

The results of our research showed that shoots rooted on MS medium without auxins produced the shortest plants with the smallest number of roots (Table 2). In plant in vitro cultures, auxins are responsible for stimulation of root development and cell elongation. However, excessive auxin concentrations added to media result in inhibition of root system development. In the course of our own research it was found that the tallest plants with the greatest mass and the longest and most developed root systems were cultured on the medium supplemented with IBA at a concentration of $1 \mathrm{mgdm}^{-3}$ (Fig. 1e). According to Nordine and El Meskaoui (2014), Nordine et al. (2013a) and Coelho et al. (2012), the most suitable medium to be used for rooting Thymus sp. is MS medium without plant growth regulators or medium supplemented with IBA at a concentration of 0.5 or $1.5 \mathrm{mgdm}^{-3}$.

The auxin often added to medium at the multiplication stage is NAA. Ozudogru et al. (2011) claimed that MS medium supplemented with $0.01 \mathrm{mgdm}^{-3} \mathrm{NAA}$ is the most efficient for rooting thyme shoots. Hosseini Behesthi and Khoushkhoui (2005) indicated that at the rooting stage of thyme in in vitro culture, the best results are obtained when the MS medium is supplemented with $0.2 \mathrm{mgdm}^{-3} \mathrm{NAA}$. However, results of the research conducted by Coehlo $\mathrm{et} \mathrm{al}$. (2012) proved that the best medium used at the rooting stage is a combination of MS medium with $1 \mathrm{mgdm}^{-3} \mathrm{NAA}$ or $0.5 \mathrm{mgdm}^{-3}$ IAA. It was found in the course of our own research that NAA added to the medium at a concentration from 0.2 to $2 \mathrm{mgdm}^{-3}$ results in development of less tall plants with roots shorter than those found in plants multiplied on the control medium.

\section{Composition of essential oils}

The essential oils obtained by hydrodistillation from in vitro shoot cultures of $T$. vulgaris were found to be yellow liquids and were obtained in a yield of $1.77 \%(\mathrm{v} / \mathrm{w})$ and $1.75 \%(\mathrm{v} / \mathrm{w})$ for Deryng and Clevenger apparatus,

Table 1. Effect of cytokinin type and concentration on proliferation of Thymus vulgaris

\begin{tabular}{|c|c|c|c|c|c|c|c|}
\hline \multicolumn{2}{|c|}{ Cytokinin concentration $\left[\mathrm{mg} \cdot \mathrm{dm}^{-3}\right]$} & \multicolumn{2}{|c|}{ Shoot length $(\mathrm{cm})$} & \multicolumn{2}{|c|}{ Shoot number } & \multicolumn{2}{|c|}{ Plant weight $(\mathrm{g})$} \\
\hline \multirow{4}{*}{ BAP } & 0.5 & 3.54 & $\mathrm{~cd}^{\mathrm{a}}$ & 11.00 & $\mathrm{~cd}$ & 0.41 & bc \\
\hline & 1.0 & 3.52 & $\mathrm{~cd}$ & 10.20 & $\mathrm{~cd}$ & 0.28 & bc \\
\hline & 2.0 & 2.67 & $\mathrm{~d}$ & 8.10 & de & 0.31 & bc \\
\hline & 5.0 & 2.60 & $\mathrm{~d}$ & 10.15 & cde & 0.46 & bc \\
\hline \multirow{4}{*}{$2 \mathrm{iP}$} & 0.5 & 4.40 & c & 12.45 & bc & 0.57 & $\mathrm{~b}$ \\
\hline & 1.0 & 4.33 & c & 15.95 & $a b$ & 1.01 & $\mathrm{a}$ \\
\hline & 2.0 & 3.48 & $\mathrm{~cd}$ & 9.60 & cde & 0.40 & bc \\
\hline & 5.0 & 4.06 & c & 16.10 & a & 0.96 & $\mathrm{a}$ \\
\hline \multirow{4}{*}{ KIN } & 0.5 & 5.67 & $\mathrm{~b}$ & 9.00 & cde & 0.21 & c \\
\hline & 1.0 & 6.56 & $\mathrm{~b}$ & 9.35 & cde & 0.41 & bc \\
\hline & 2.0 & 6.59 & $b$ & 7.75 & de & 0.31 & bc \\
\hline & 5.0 & 6.03 & $\mathrm{~b}$ & 7.71 & de & 0.37 & bc \\
\hline Control & - & 8.73 & $\mathrm{a}$ & 6.65 & e & 0.32 & bc \\
\hline
\end{tabular}

${ }^{a}$ Values followed by the same letter are not significantly different at $\mathrm{P} \leq 0.05$ according to the LSD Duncan test. 
Table 2. Effect of auxin type and concentration on shoot rooting of Thymus vulgaris

\begin{tabular}{|c|c|c|c|c|c|c|c|c|c|}
\hline \multicolumn{2}{|c|}{ Auxin concentration $\left[\mathrm{mg} \cdot \mathrm{dm}^{-3}\right]$} & \multicolumn{2}{|c|}{ Roots length $[\mathrm{cm}]$} & \multicolumn{2}{|c|}{ Roots number } & \multicolumn{2}{|c|}{ Shoot length $[\mathrm{cm}]$} & \multicolumn{2}{|c|}{ Plant weight $[\mathrm{g}]$} \\
\hline \multirow{4}{*}{ IBA } & 0.2 & 2.46 & $\mathrm{~b}^{\mathrm{a}}$ & 2.15 & bcd & 5.79 & $\mathrm{~b}$ & 0.056 & $\mathrm{~cd}$ \\
\hline & 0.5 & 2.43 & b & 2.35 & bcd & 4.99 & $\mathrm{bc}$ & 0.064 & $\mathrm{~cd}$ \\
\hline & 1.0 & 4.00 & $\mathrm{a}$ & 7.80 & a & 9.29 & $\mathrm{a}$ & 0.170 & $\mathrm{a}$ \\
\hline & 2.0 & 2.14 & $\mathrm{~b}$ & 2.55 & bc & 3.39 & def & 0.080 & bcd \\
\hline \multirow{5}{*}{ IAA } & 0.2 & 0.65 & d & 1.89 & $\mathrm{~cd}$ & 2.31 & ef & 0.076 & bc \\
\hline & 0.5 & 1.12 & $\mathrm{~cd}$ & 2.01 & bcd & 3.25 & ef & 0.081 & $\mathrm{bc}$ \\
\hline & 1.0 & 1.06 & $\mathrm{~cd}$ & 2.65 & $\mathrm{bc}$ & 4.69 & $\mathrm{bc}$ & 0.109 & b \\
\hline & 2.0 & 1.11 & $\mathrm{~cd}$ & 1.98 & bcd & 4.03 & $\mathrm{~cd}$ & 0.096 & $\mathrm{~b}$ \\
\hline & 0.2 & 1.16 & $\mathrm{~cd}$ & 2.10 & bcd & 4.12 & $\mathrm{~cd}$ & 0.054 & $\mathrm{~cd}$ \\
\hline \multirow{3}{*}{ NAA } & 0.5 & 1.43 & c & 2.00 & bcd & 3.02 & ef & 0.050 & d \\
\hline & 1.0 & 1.14 & $\mathrm{~cd}$ & 2.45 & $\mathrm{bc}$ & 3.64 & de & 0.076 & $\mathrm{bcd}$ \\
\hline & 2.0 & 0.56 & $\mathrm{~d}$ & 1.70 & d & 3.18 & ef & 0.065 & $\mathrm{~cd}$ \\
\hline Control & - & 2.33 & $\mathrm{~b}$ & 1.70 & d & 2.05 & f & 0.050 & d \\
\hline
\end{tabular}

${ }^{\bar{a}}$ Values followed by the same letter are not significantly different at $\mathrm{P} \leq 0.05$ according to the LSD Duncan test.

respectively. Obtained results are in conformity with the European Pharmacopoeia standard for Thymi herba (a yield of at least 1.2\%) (European Pharmacopoeia 2010). The relative amounts of the volatile components identified in the extracted oils are presented in Table 3, in the order of their elution from the HP-5MS column.

In total, 54 different compounds were identified in the essential oils obtained by hydrodistillation in Deryng and Clevenger apparatus from in vitro shoot cultures of thyme, constituting 99.56-99.57\% of the oils.

The major constituents of the oil obtained in Deryng apparatus were thymol (33.37\%), $\gamma$-terpinene (11.91\%), pcymene $(9.81 \%)$, carvacrol (5.63\%), carvacrol methyl ether (3.87\%) and linalool (3.36\%). Among the other components found in significant amounts were thymol acetate (3.19\%), $\beta$-caryophyllene (2.99\%), $\alpha$-terpinene $(2.88 \%)$ and borneol (2.25\%). Similarly, thymol (34.05\%) dominated in the essential oil obtained in Clevenger apparatus. Other abundant constituents were $\gamma$-terpinene (11.62\%), p-cymene (10.07\%), carvacrol (5.96\%), carvacrol methyl ether (3.86\%) and $\beta$-caryophyllene (3.59\%). The oil also contained thymol acetate $(3.15 \%)$ and $\alpha$-terpinene (2.82\%).

Our results indicate that the major components identified in both oils were the same (Table 4). However, the highest amounts of thymol (34.05\%), p-cymene (10.07\%), carvacrol (5.96\%) and $\beta$-caryophyllene (3.59\%) were noted in the oil obtained in Clevenger apparatus, while the highest concentration of $\gamma$-terpinene (11.91\%) was detected in the oil obtained in Deryng apparatus. Considering the main chemical classes of compounds, the most plentiful were oxygenated monoterpenes (56.81$57.28 \%)$ and monoterpene hydrocarbons (31.90-33.72\%) (Table 3).

Table 4. Statistical analysis of the content of main constituents of essential oil of thyme in dependence on distillation apparatus

\begin{tabular}{|c|c|c|c|}
\hline \multirow{2}{*}{ Essential oil constituent (factor $I$ ) } & \multicolumn{2}{|c|}{ Distillation apparatus (factor II) } & \multirow{2}{*}{ Mean } \\
\hline & Deryng & Clevenger & \\
\hline$\alpha$-Thujene & 2.07 & 1.55 & 1.81 \\
\hline$\alpha$-Pinene & 1.35 & 0.89 & 1.12 \\
\hline Camphene & 1.13 & 0.65 & 0.89 \\
\hline 1-Octen-3-ol & 1.29 & 1.21 & 1.25 \\
\hline$\beta$-Myrcene & 1.73 & 1.65 & 1.69 \\
\hline$\alpha$-Terpinene & 2.88 & 2.82 & 2.85 \\
\hline p-Cymene & 9.81 & 10.07 & 9.94 \\
\hline Eucalyptol & 1.08 & 0.99 & 1.04 \\
\hline$\gamma$-Terpinene & 11.91 & 11.62 & 11.77 \\
\hline cis-Sabinene hydrate & 1.57 & 1.68 & 1.63 \\
\hline Linalool & 3.36 & 3.16 & 3.26 \\
\hline Camphor & 1.14 & 0.91 & 1.03 \\
\hline Borneol & 2.25 & 1.53 & 1.89 \\
\hline Carvacrol methyl ether & 3.87 & 3.86 & 3.87 \\
\hline Thymol & 33.37 & 34.05 & 33.71 \\
\hline Carvacrol & 5.63 & 5.96 & 5.80 \\
\hline Thymol acetate & 3.19 & 3.15 & 3.17 \\
\hline$\beta$-Caryophyllene & 2.99 & 3.59 & 3.29 \\
\hline Germacrene D & 0.87 & 1.04 & 0.96 \\
\hline Mean & 4.82 & 4.76 & 4.79 \\
\hline $\mathrm{LSD}_{a=0.05}$ for factor I & 0.95 & & \\
\hline $\mathrm{LSD}_{\alpha=0.05}$ for factor II & r.n. & & \\
\hline $\mathrm{LSD}_{\alpha=0.05}$ for interaction Ix II & r.n. & & \\
\hline
\end{tabular}


530

Table 3. Composition of Thymus vulgaris $\mathrm{L}$. oil in dependence on distillation apparatus

\begin{tabular}{|c|c|c|c|c|}
\hline No. & Compound & RI & Deryng & Clevenger \\
\hline 1. & Methyl $\alpha$-methylbutanoate & $<800$ & 0.12 & 0.07 \\
\hline 2. & $\alpha$-Tricyclene & 921 & 0.05 & - \\
\hline 3. & $\alpha$-Thujene & 927 & 2.07 & 1.55 \\
\hline 4. & $\alpha$-Pinene & 933 & 1.35 & 0.89 \\
\hline 5. & Camphene & 948 & 1.13 & 0.65 \\
\hline 6. & $\beta$-Thujene (Sabinene) & 973 & 0.19 & 0.15 \\
\hline 7. & $\beta$-Pinene & 976 & 0.41 & 0.34 \\
\hline 8. & 1-Octen-3-ol & 980 & 1.29 & 1.21 \\
\hline 9. & 3-Octanone & 987 & 0.09 & 0.08 \\
\hline 10. & $\beta$-Myrcene & 991 & 1.73 & 1.65 \\
\hline 11. & 3-Octanol & 996 & 0.33 & 0.25 \\
\hline 12. & $\alpha$-Phellandrene & 1004 & 0.40 & 0.37 \\
\hline 13. & 3-Carene & 1010 & 0.16 & 0.15 \\
\hline 14. & $\alpha$-Terpinene & 1016 & 2.88 & 2.82 \\
\hline 15. & p-Cymene & 1025 & 9.81 & 10.07 \\
\hline 16. & $\beta$-Phellandrene & 1029 & 0.89 & 0.90 \\
\hline 17. & Eucalyptol (1,8-Cineole) & 1031 & 1.08 & 0.99 \\
\hline 18. & (Z)- $\beta$-Ocimene & 1038 & 0.31 & 0.33 \\
\hline 19. & (E)- $\beta$-Ocimene & 1049 & 0.20 & 0.19 \\
\hline 20. & $\gamma$-Terpinene & 1061 & 11.91 & 11.62 \\
\hline 21. & cis-Sabinene hydrate & 1067 & 1.57 & 1.68 \\
\hline 22. & $\alpha$-Terpinolene & 1089 & 0.23 & 0.22 \\
\hline 23. & Linalool & 1100 & 3.36 & 3.16 \\
\hline 24. & $\beta$-Thujone & 1114 & 0.10 & - \\
\hline 25. & Camphor & 1147 & 1.14 & 0.91 \\
\hline 26. & Borneol & 1168 & 2.25 & 1.53 \\
\hline 27. & Terpinen-4-ol & 1181 & 0.84 & 0.74 \\
\hline 28. & $\alpha$-Terpineol & 1196 & 0.33 & 0.27 \\
\hline 29. & Dihydrocarvone & 1203 & 0.11 & 0.05 \\
\hline 30. & Borneolformate & 1231 & 0.05 & 0.04 \\
\hline 31. & Thymol methyl ether & 1235 & 0.20 & 0.21 \\
\hline 32. & Carvacrol methyl ether & 1245 & 3.87 & 3.86 \\
\hline 33. & Carvone & 1258 & 0.14 & 0.16 \\
\hline 34. & Borneol acetate & 1288 & 0.05 & 0.05 \\
\hline 35. & Thymol & 1299 & 33.37 & 34.05 \\
\hline 36. & Carvacrol & 1304 & 5.63 & 5.96 \\
\hline 37. & Thymol acetate & 1356 & 3.19 & 3.15 \\
\hline 38. & $\alpha$-Copaene & 1380 & 0.11 & 0.11 \\
\hline 39. & $\beta$-Caryophyllene & 1426 & 2.99 & 3.59 \\
\hline 40. & $\beta$-Cubebene & 1435 & 0.07 & 0.08 \\
\hline 41. & $\alpha$-Caryophyllene & 1460 & 0.14 & 0.18 \\
\hline 42. & $\gamma$-Muurolene & 1482 & 0.11 & 0.16 \\
\hline 43. & Germacrene D & 1487 & 0.87 & 1.04 \\
\hline 44. & Virdiflorene & 1502 & 0.08 & 0.08 \\
\hline 45. & $\alpha$-Muurolene & 1505 & 0.09 & 0.15 \\
\hline 46. & $\gamma$-Cadinene & 1520 & 0.13 & 0.19 \\
\hline 47. & $\delta$-Cadinene & 1529 & 0.33 & 0.45 \\
\hline 48. & Spathulenol & 1584 & 0.21 & 0.32 \\
\hline 49. & Caryophylleneoxide & 1592 & 0.42 & 0.38 \\
\hline 50. & $\gamma$-Eudesmol & 1630 & 0.50 & 0.58 \\
\hline 51. & $\tau$-Cadinol & 1654 & 0.14 & 0.21 \\
\hline 52. & $\alpha$-Cadinol & 1667 & 0.30 & 0.35 \\
\hline 53. & 5-Methylheneicosane & 2146 & - & 0.92 \\
\hline \multirow[t]{7}{*}{54.} & 1-Nonadecanol & 2166 & 0.25 & 0.45 \\
\hline & Total identified & & 99.57 & 99.56 \\
\hline & Monoterpene hydrocarbons & & 33.72 & 31.90 \\
\hline & Oxygenated monoterpenes & & 57.28 & 56.81 \\
\hline & Sesquiterpene hydrocarbons & & 4.92 & 6.03 \\
\hline & Oxygenated sesquiterpenes & & 1.57 & 1.84 \\
\hline & Others & & 2.08 & 2.98 \\
\hline
\end{tabular}

RI: retention indices relative to $\mathrm{n}$-alkanes $\left(\mathrm{C}_{7}-\mathrm{C}_{40}\right)$ on HP-5MS column 
According to European Pharmacopoeia requirements, the amount of $\gamma$-terpinene, p-cymene, linalool, thymol and carvacrol in Thymi aetheroleum should be 5-10\%, 15-28\%, $4-6.5 \%, 36-55 \%$, and 1-4\%, respectively (European Pharmacopoeia 2010).

The amounts of p-cymene and thymol recorded in the investigated oils were slightly lower than the European Pharmacopoeia limit; however, the percentage of linalool was found to be within the desired range. The percentage content of $\gamma$-terpinene and carvacrol was found to be much higher than that specified by the European Pharmacopoeia.

A survey of the literature showed remarkable differences in the essential oil composition of Thymus vulgaris L. from different origins. In the essential oil from $T$. vulgaris growing wild in Turkey, thymol (46.2\%), $\gamma$-terpinene (14.1\%), p-cymene (9.9\%) and linalool (4.0\%) (Ozcan and Chalchat, 2004) were the major components, while the oil from plants collected in Egypt contained mainly carvacrol (48.23\%), thymol (12.74\%) and borneol (4.92\%) (Hemada and El-Darier, 2011). Thymol (61.6\%), p-cymene (11.2\%), $\gamma$-terpinene $(7.4 \%)$ and $\beta$-caryophyllene $(2.3 \%)$ dominated in the oil from the Western Ghats of India (Syamasundar $e t$ al., 2008). Similarly, thymol (44.7\%), p-cymene (18.6\%) and $\gamma$-terpinene $(16.50 \%)$ were found as the major components of thyme oil from Brazil (Porte et al., 2008). T. vulgaris grown in south-eastern Poland was characterised by the presence of thymol (49.9-61.2\%), $\gamma$-terpinene (11.3$12.1 \%)$, p-cymene (9.1-13.5\%) and carvacrol (5.0-6.3\%) (Zawislak, 2007).

Such quantitative differences in the content of major biologically active constituents in the oils of thyme obtained from different geographical sources may cause different pharmacological effects of these medicinal plants. Due to this fact, it can be concluded that plants derived from in vitro cultures may be an excellent source of standardised essential oils. Moreover, these plants may be used in different studies without obtaining them from the natural environment or reproduction of seeds.

\section{Acknowledgements}

This study was supported by the Polish Ministry of Science and Higher Education, within the project UPB 518-07-017-3171-01/18 ZUT.

\section{References}

Adams RP (2007). Identification of essential oil components by gas chromatography/mass spectrometry. Allured Publishing Corporation, 4thed.USA pp 54401.

Andrys D, Kulpa D (2017). In vitro propagation affects the composition of narrow-leaved lavender essential oils. Acta Chromatographica 1-6.

Andrys D, Kulpa D, Grzeszczuk M, Bihun M, Dobrowolkka A (2017). Antioxidant and antimicrobial activities of Lavandula angustifolia Mill. field-grown and propagated in vitro. Folia Horticulturae 29(2):161-180.

Bakhtiar Z, Mirjalili MH, Sonboli A, Moridi Farimani M, Ayyari M (2014). In vitro propagation, genetic and phytochemical assessment of Thymus persicus - a medicinally important source of pentacyclictriterpenoids. Biologia 69(5):594-603.
Bernard F, Moghadam NN, Mirzajani F (2015). The effect of colloidal silver nanoparticles on the level of lignification and hyperhydricity syndrome in Thymus daenensis in vitro shoots: a possible involvement of bonded polyamines. In Vitro Cellular and Developmental Biology - Plant 51:546-553.

Blum C, Kubeczka KH, Becker K (1997). Supercritical fluid chromatography-mass spectrometry of thyme (Thymus vulgaris L.). Journal of Chromatography A 773:377-380.

Coelho N, Goncalves S, Gonzalez-Benito ME, Romano A (2012). Establishment of an in vitro propagation protocol for Thymus lotocephalus, a rare aromatic species of the Algarve (Portugal). Plant Growth Regulation 66:69-74.

Cosentino S, Tubeerso CIG, Pisano B, Satta M, Mascia V, Arzedi E, Palmas $\mathrm{F}$ (1999). In vitro antimicrobial activity and chemical composition of Sardinian Thymus essential oils. Letters in Applied Microbiology 29:130-135.

Deans SG, Ritchie G (1987). Antibacterial properties of plant essential oils. International Journal of Food Microbiology 5:165-180.

European Pharmacopoeia (2010). European Pharmacopoeia, 7th edition. Strasbourg, Council ofEuropepp 1252-1254.

Fraternale D, Giamperi L, Ricci D, Rocchi MBL, Guidi L, Epifano F, Marcotullio MC (2003). The effect of triacontanol on micropropagation and on secretory system of Thymus mastichina. Plant Cell Tissue Organ Cultures 74:87-97.

Furmanowa M, Olszowska O (1980). Thymus vulgaris L propagation through tissue culture. Acta Poloniae Pharmaceutica37(2):242-247.

Furmanowa M, Olszowska O (2009). Micropropagation of thyme (Thymus vulgaris L.) III. Biotechnology in agriculture and forestry. High-Tech and Micropropagation 19:230-243.

Gounaris Y (2010). Biotechnology for the production of essential oils, flavours and volatile isolates. A review. Flavour and Fragrance Journal 25:367-386.

Grigore A, Parasachiv I, Colceru S, Babuneau C, Draghici E, Ichim M (2010). Chemical composition and antioxidant activity of Thymus vulgaris $\mathrm{L}$. volatile oil obtained by two different methods. Romanian Biotechnology Letters 15:5436-5443.

Hassannejad S, Bernard F, Mirzajani F, Gholami M (2012). SA improvement of hyperhydricity reversion in Thymus daenensis shoots culture may be associated with polyamines changes. Plant Physiology and Biochemistry 51:40 46 .

Hazzit M, Balliouamer A, Verissimo AR, Falerio ML, Miguel MG (2009). Chemical composition and biological activities of Algerian Thymus oils. Food Chemistry 116:714721.

Hemada M, El-Darier S (2011). Comparative study on composition and biological activity of essential oils of two Thymus species grown in Egypt. American-Eurasian Journal of Agricultural \& Environmental Sciences 11:647-654.

Karalija E, Parić A (2011). The effect of BA and IBA on the secondary metabolite production by shoot culture of Thymus vvlgaris L. Biology Nyssana 2(1):29-35.

Lee SJ, Umano K, Shibamoto T, Lee KG (2005). Identification of volatile components in basil (Ocimum basilicum $\mathrm{L}$ ) and thyme leaves (Thymus vulgaris $\mathrm{L}$.) and their antioxidant properties. FoodChemistry 91:131-137. 
532

Leung AY, Foster S (1996). Encyclopedia of common natural ingredients used in food, drugs and cosmetics. John Wiley \& Sons, New York.

Marco-Medina A, Casas JL (2015). In vitro multiplication and essential oil composition of Thymus moroderi Pau ex Martinez, an endemic Spanish plant. Plant Cell Tissue Organ Cultures 120:99-108.

Matkowski A (2008). Plant in vitro culture for the production of antioxidants - a review. Biotechnology Advances 26:548-560.

Mendes MD, Figueiredo AC, Oliveira MM, Trindade H (2013). Essential oil production in shoot cultures versus field-grown plants of Thymus caespititius. Plant Cell Tissue Organ Cultures 113:341-351.

Mendes ML, Romano A (2009). In vitro cloning of Thymus mastichana L. field-grown plants. International Society Horticultural Sciences 505: 303-306.

Mirzaei-Aghsaghali A, Alireza Syadati S, Fathi H (2012). Some of thyme (Thymus vulgaris) properties in ruminant's nutrition. Annals of Biology Researches 3(2):1191-1195.

Muraskige T, Skoog F (1962) A revised medium for rapid growth and bio assays with tobacco tissue cultures. Physiologia Plantarum 15(3):473497.

Nickavar B, Mojab F, Dolat-Abadi R (2005). Analysis of the essential oils of two Thymusspecies from Iran. Food Chemistry 90:609-611.

Nicolič M, Glamočlia J, Ferreria ICFR, Calhelha CR, Fernandes Â, Markovič D, Markovič T, Giweli A, Sokovič M (2014). Chemical composition, antimicrobial, antioxidant and antitumor activity of Thymus serpyllum L. Thymus algeriensis Boiss. and Reut and Thymus vulgaris L. essential oill. Industrial Crop Products 52:183-190.

Nordine A, Bousta D, El Khanchoufi A, El Meskaoui A (2013a). An efficient and rapid in vitro propagation system of Thymus hyemalis lange, a wild medicinal and aromatic plant of Mediterranean region. International Journal of Pharma Bioscience and Technology 1(3):118129.

Nordine A, Rachida TCh, El Meskaoui A (2013b). Micropropagation of Thymus satureioides Coss. an endangered medicinal plant of Morocco. Journal of Agricultural Science and Technology 9(2):487-501.

Nordine A, El Meskaoui A (2014). Rapid in vitro regeneration and clonal multiplication of Thymus bleicherianus Pomel, a rare and threatened medicinal and aromatic plant in Morocco. Medicinal and Aromatic Plants 3:145.

Olszowska O, Furmanowa M (1987). Micropropagation of thyme (Thymusvulgaris L.) from nodal segments. Herba Polonica 33:137-144.
Olszowska O (1982). Vegetative propagation of Thymus vulgaris L. in tissue culture and estimation of selected strains. $\mathrm{PhD}$ Thesis. Medical Academy Warsaw.

Ozcan M, Chalchat JC (2004). Aroma profile of Thymus vulgaris L. growingwild in Turkey. Bulgarian Journal of Plant Physiology30:68-73.

Ozudogru EA, Ergun K, Ermah K, Issever-Oztruk S (2011). In vitro propagation from young and mature explants of thyme (Thymus vulgaris and T. longicaulis) resulting in genetically stable shoots. In Vitro Cellular and Developmental Biology - Plant 37:309-320.

Pérez-Tortosa V,López-Orenes A, Martínez-Pérez A, Ferrer MA, Calderón AA (2012). Antioxidant activity and rosmarinic acid changes in salicylic acid-treated Thymus membranaceus shoots. Food Chemistry 130:362369.

Polish Pharmacopoeia (2001). Polish Pharmacopoeia VI. Warszawa pp 897 900.

Porte A, Ronoel L, Godoy O (2008). Chemical composition of Thymus vulgaris L. (thyme) essential oil from Rio de Janeiro State (Brazil). Journal of the Serbian Chemical Society 73:307-310.

Sáez F, Sánchez P, Piqueras A (1994). Micropropagation of Thymus piperella.Plant Cell, Tissue and Organ Culture 39:269-272.

Sargsyan E, Vardanyan A, Ghalachyan L, Bulgadaryan S (2011). Cultivation of thymus by in vitro and hydroponics combined method. World Academy of Science, Engineering and Technology 80:129-132.

Syamasundar KV, Srinivasulu B, Stephen A, Ramesh S. Rao RR (2008). Chemical composition of volatile oil of Thymus vulgaris L from Western Ghats of India. Journal of Herbs, Spices and Medicinal Plants $17: 255-258$.

Tabak M, Armon R, Potasman I, Neeman I (1996). In vitro inhibition of Helicobacterpyroli by extracts of thyme.Journal of Applied Microbiology 80:667-672.

Tavan M, Mirjalili MH, Karimzadeh G (2015). In vitro polyploidy induction: changes in morphological, anatomical and phytochemical characteristics of Thymus persicus (Lamiaceae). Plant Cell, Tissue and Organ Culture 122:573-583.

Zawislak G (2007). Analysis of chemical composition of essential oil in the herb of thyme (Thymus vulgaris L.) grown in south-eastern Poland. HerbaPolonica 53(3):241-245. 